\title{
High-density areas for harbor porpoises (Phocoena phocoena) identified by satellite tracking
}

\author{
Signe SVEEgaARD \\ JONAS TEILMANN \\ JAKOB TOUGAARD \\ RUNE DIETZ \\ National Environmental Research Institute (NERI), \\ Department for Arctic Environment, \\ Aarhus University, \\ Frederiksborgvej 399, DK-4000 Roskilde, Denmark \\ E-mail:sign@dmu.dk \\ KIM N. MOURITSEN \\ Department of Biological Sciences, \\ Marine Ecology, \\ Aarhus University, \\ Ole Worms Allé 1, DK-8000 Aarhus C, Denmark \\ GeneViève Desportes \\ Fjord \& Belt Center and Gdnatur, \\ DK-5300, Kerteminde, Denmark

\section{URSUla Siebert} \\ Research and Technology Center Westcoast, \\ Christian-Albrechts-University Kiel, \\ Werftstrasse 6, GE-25761 Büsum, Germany
}

\begin{abstract}
The population status of harbor porpoises has been of concern for several years, and the establishment of Marine Protected Areas (MPAs) has been suggested as a method to protect the harbor porpoise (Phocoena phocoena, Linneaus 1758) and other small cetaceans. In order to designate MPAs, high-density areas for the species must be identified. Spatial distribution of small cetaceans is usually assessed from ship or aerial surveys. As a potentially more accurate alternative, this study examined the movements and area preferences of 64 harbor porpoises, satellite tagged between 1997 and 2007, in order to determine the distribution in the North Sea, the western Baltic, and the waters in between. Results show that harbor porpoises are not evenly distributed, but congregate in nine high-density areas within the study area. Several of these areas are subject to significant seasonal variation. The study found no differences in the home range size of males and females, but immature harbor porpoises have larger home ranges than mature porpoises. The use of satellite telemetry for
\end{abstract}


identifying areas of high harbor porpoise density can be of key importance when designating MPAs.

Key words: harbor porpoise, Phocoena phocoena, small cetacean, conservation, kernel density estimation, key habitat, Marine Protected Area.

In the last few decades, the need to protect small cetaceans in order to maintain sustainable populations has become increasingly apparent. Small cetaceans, such as the harbor porpoise (Phocoena phocoena, Linneaus 1758) face threats of incidental bycatch in fishing gear (e.g., Vinther and Larsen 2004), pollution, food depletion (Reijnders 1992), and other anthropogenic disturbances such as underwater noise, shipping, oil and gas exploration, as well as construction at sea including bridges and offshore wind farms (e.g., Carstensen et al. 2006).

The establishment of Marine Protected Areas (MPAs) has been suggested as a method to protect small cetaceans (e.g., Hoyt 2005). In the EU, all relevant member states are legally obliged to protect the harbor porpoise by designating MPAs, referred to as Special Areas of Conservation (SAC) according to the EC Habitat Directive (92/43/EEC 1992). The designation of marine SAC in the EU is scheduled to be completed by 2012 (European Commission 2007).

A first step toward designation of MPAs for cetaceans is to identify the key habitats of the target species. Key habitats refer to those parts of a species' range that are essential for day-to-day survival, as well as for maintaining a healthy population growth rate (92/43/EEC 1992). Areas that are regularly used for feeding, breeding, raising calves, and migration are all part of the key habitats (sensu Hoyt 2005). For the harbor porpoise, knowledge of the physical and biological factors defining key habitats is currently insufficient. It may, however, be assumed that the areas with the highest porpoise densities are also the areas where factors essential to life and reproduction are best fulfilled (European Commission 2007). Hence, the designation of MPAs may be based on the density of harbor porpoises.

Until recently, distribution of small cetaceans has mostly been estimated visually by ship and aerial surveys (Heide-Jørgensen et al. 1992, 1993, Hammond et al. 2002, Scheidat et al. 2004). However, visual surveys can only be conducted in daylight under calm weather conditions, which generally limits large-scale surveys to the summer months (Hammond et al. 2002, Teilmann 2003). In the last decade, acoustic surveys, in which an array of hydrophones is towed behind a vessel, have been applied (Gillespie et al. 2005). The hydrophones record the echolocation clicks emitted by the porpoises and can thereby provide a relative measure of abundance also under less favorable weather conditions. In Germany, aerial surveys intended to identify MPAs for harbor porpoises were successfully supplemented in areas of low density by stationary acoustic data loggers (T-PODs) (Verfuss et al. 2007).

In the North Sea, the western Baltic, and the waters in between, two large-scale studies of porpoise distribution have been conducted, namely the two Small Cetacean Abundance in the North Sea (SCANS) surveys in 1994 and 2005 (Hammond et al. 2002, Anonymous 2006). These were, however, not detailed enough for small-scale identifications of high-density areas, but intended for large-scale abundance estimation of porpoises in European waters. In the last decade, satellite tagging has been conducted in order to investigate harbor porpoise movement, behavior, and presence in relation to environmental factors (Teilmann et al. 2007, Edrén et al., 
in press). Satellite tracking can provide detailed information on individual movements for up to a year and has the advantage of combining temporal and spatial information on a broader scale.

This study uses satellite telemetry data collected from 64 individual porpoises over a 10-yr period to identify key habitat use from the North Sea through Skagerrak, Kattegat, and Belt seas to the western Baltic.

\section{Materials AND Methods}

\section{Study Area}

The study area was divided into two areas based on tagging locations and lack of porpoise movements between the two areas: (1) the southern Kattegat, Belt Sea, and western Baltic (defined as the Inner Danish Waters, hereafter IDW) and (2) northern Kattegat, Skagerrak, and northeastern North Sea (defined as the waters north of Læs $\varnothing$, hereafter Skagerrak) (Fig. 1). The main part of the IDW is between 10 and $40 \mathrm{~m}$ deep and due to the many islands the only passage from the Baltic proper to Kattegat is through the narrow straits of Little Belt $(<2 \mathrm{~km}$ wide), Great Belt (18 km wide), and Øresund $(<7 \mathrm{~km})$. The North Sea and Skagerrak includes deeper waters, in particular, the Norwegian Trench that runs along the Norwegian/Danish border and represents a sudden drop in depth from 100 to $700 \mathrm{~m}$.

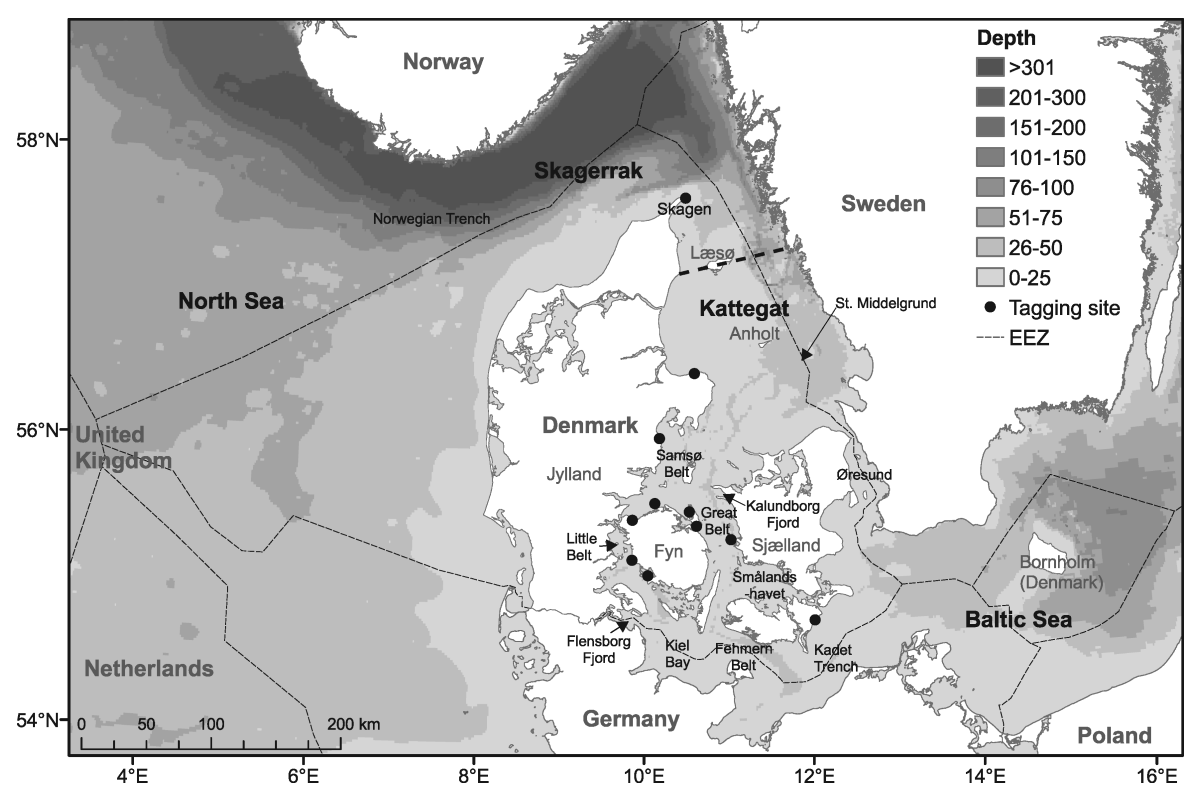

Figure 1. Map of the study area with names mentioned in the text indicated. The locations of the pound nets where the harbor porpoises, Phocoena phocoena, were caught and tagged are indicated with black dots. The bold dashed line indicates the division of Skagerrak and the Inner Danish waters. Thin dashed line indicates international Exclusive Economic Zones (EEZ). Map projection universal transverse Mercator, Zone 32N, WGS84. 


\section{Satellite Tagging of Harbor Porpoises}

Twenty-four harbor porpoises were tagged at Skagen on the northern tip of Jylland between May 2000 and September 2003 and 40 harbor porpoises were tagged in IDW from April 1997 to October 2007 (Fig. 1). The porpoises were either assigned to the IDW group or the Skagerrak group depending on where the majority of the tracking period was spent. This assignment was performed to objectively categorize the porpoises tagged in Kattegat near the border between the two groups (Fig. 1).

Porpoises were caught incidentally in pound nets. A pound net is a Danish type of trap fishery consisting of a long net of up to $1 \mathrm{~km}$ leading the fish such as herring (Clupea harengus), mackerel (Scomber scombrus), garfish (Belone belone), and eel (Anguilla anguilla) from shore toward the main net. The main net consists of several compartments each leading the fish or porpoise further into the net. The last of the main nets is constructed in the shape of a pot allowing the trapped porpoise to breathe at the surface.

Harbor porpoises were usually tagged within $24 \mathrm{~h}$ of being discovered by the fisherman. Six different types of transmitters were used: Telonics ST-10 and ST18; Wildlife Computers SDR-T10, SDR-T16, and SPOT2; and Sirtrack Kiwi 101, taking advantage of technical developments over the 10 -yr study period so the smallest and most hydrodynamic tags were always used. All transmitters used the Argos system. Tags were duty cycled to transmit every 1, 2, 3, or $4 \mathrm{~d}$ and programmed to give 50-1,000 transmissions per duty day (Teilmann et al. 2008). The transmitters weighed $105-240 \mathrm{~g}$ in air. Prior to attachment, the dorsal fin was anaesthetized with $5 \%$ lidocaine salve. Each transmitter was attached by perforating the fin using a $6-\mathrm{mm}$ cork borer and subsequently fastening the transmitter using 2-3 polyoxymethylen $5-\mathrm{mm}$ pins covered with silicone tubes. The pins were attached to the transmitter on one side of the dorsal fin and secured with a backing plate and iron nuts on the opposite side to allow the transmitter to detach after about $1 \mathrm{yr}$. The animal was released after about $30 \mathrm{~min}$ (for more details on tagging procedure and effects of tagging, see Geertsen et al. 2004, Teilmann et al. 2007, and Eskesen et al. 2009).

Contact with the porpoises was not evenly distributed throughout the year because the majority of animals were tagged in spring (March-May), which is the main season for the pound net fishery (Table 1).

\section{Data Analysis}

The locations of the tagged animals were determined by the ARGOS system maintained by Service Argos. Locations are classified by the Argos system into one of six location classes (LC) according to level of accuracy (3, 2, 1, 0, A, B) measured in kilometers of uncertainty for latitude and longitude, respectively. Studies have shown that there can be significant error in all LCs (up to several kilometers), but that even the low-accuracy locations may provide useful and valid information if they are appropriately filtered (e.g., Vincent et al. 2002). Thus, all LCs were used in this study after being filtered by an SAS-routine, Argos-Filter v7.03 (Douglas 2006). The filter is a Distance-Angle-Rate (DAR) filter and applies user-defined settings for distance between successive locations, turning angles and maximum swim speed to filter out the most unlikely locations. The filter is comparable to the R-based Speed, Distance, Angle (SDA) filter tested by Freitas et al. (2008). They found that this type of filter was very efficient at removing unrealistic low-accuracy locations $(0, A$, and $B$ as defined by Argos), but preserved a significantly higher percentage of high-accuracy 


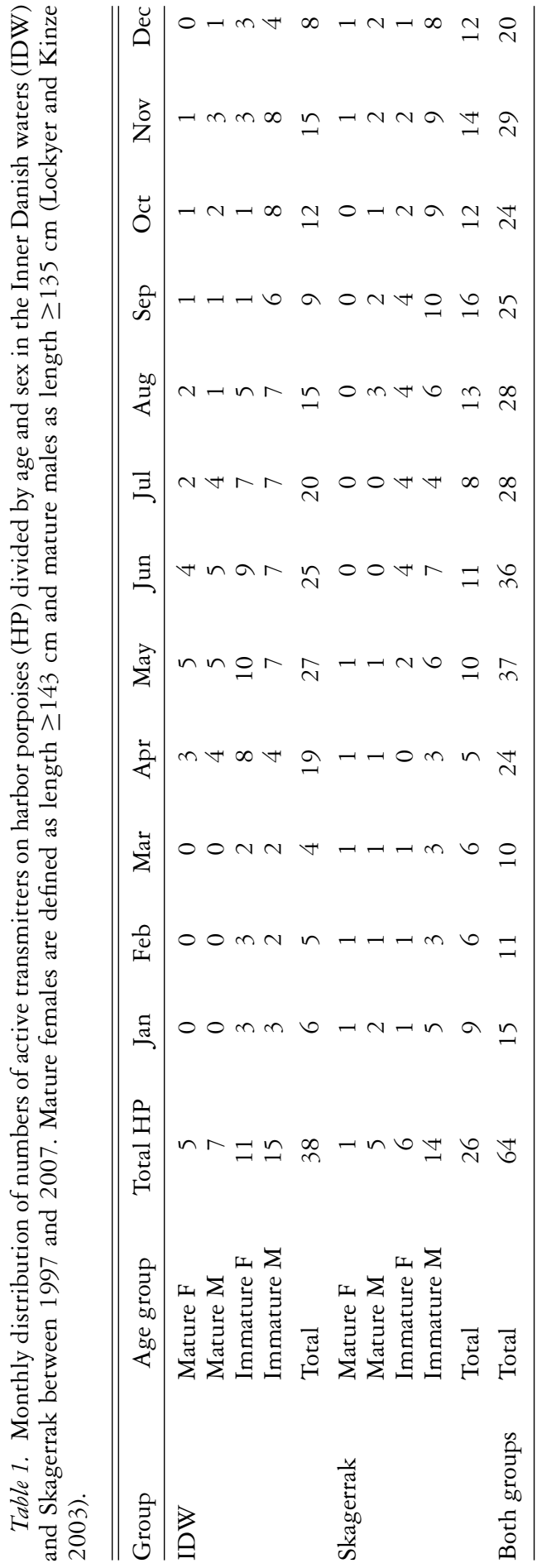


locations (1, 2, and 3) than filters only based on swimming speed, such as the filter used by Vincent et al. (2002). Filter test of our data gave similar results and it was concluded that the DAR filter was appropriate for the analysis in this study. For an example of the DAR filtering method, see Appendix 1 in the online supplementary material. The filter settings for this study were: maxredun $=5$ (distance between locations in kilometers. If two locations are within close distance of each other, here $<5 \mathrm{~km}$, they are both retained, because the likelihood of both being wrong is small), minrate $=10$ (maximum swim speed, kilometer/hour. Locations leading to swim rates $>10 \mathrm{~km} / \mathrm{h}$ are excluded), ratecoef $=10$ (angle between vector lines to previous and following location, that is, if this angle is $<10^{\circ}$ the location is excluded). The minrate value was selected based on velocity measurements of a wild harbor porpoise where average speed was $5.3 \mathrm{~km} / \mathrm{h}$ and close to $95 \%$ of all recordings were less than $10 \mathrm{~km} / \mathrm{h}$ (Teilmann 2000). The value of $10 \mathrm{~km} / \mathrm{h}$ was chosen to avoid overestimation of high swimming speed. All other settings were set as default. Locations from all six LCs were filtered and the most accurate location was selected for each day resulting in a total number of 4,583 locations. Daily locations were selected automatically from the filtered dataset by the Argos Filter routine based on LC level and number of uplinks per transmission.

Wildlife telemetry data are inherently spatially and temporally nonindependent because sequentially collected telemetry locations are serially correlated and animals may display individual behavior. Thus, pooling all data is only justifiable when behavior do not differ between individuals (Aebischer et al. 1993), which can not be ruled out in this study. Consequently, this study applied two techniques: (1) by weighing each animal equally in the analysis (Fieberg 2007) the porpoise becomes the sampling unit instead of the telemetry location, and pooling of data across individuals is avoided (Aebischer $e t$ al. 1993. For further information on weighing, see Appendix 2 in the online supplementary material) and (2) the data sets were subsampled according to calculated time to independence, that is, the minimum time it takes for an animal to cross its entire range (Rooney et al. 1998). In this study, porpoises were recorded traveling up to $100 \mathrm{~km} / \mathrm{d}$ in a straight line. The distance from Skagen to Kiel Bay, that is, the home range of the IDW group is approximately $380 \mathrm{~km}$. Thus, only locations from every fourth day for each individual were used in the analysis.

Furthermore, to avoid overrepresentation of the area of the tagging site, the average daily distance from the deployment site were plotted for all individuals. A tree-regression analysis (Crawley 2002) showed that days 0-4 deviated significantly from day 5 and onward. Consequently, all locations from days $0-4$ were removed from the analysis.

The telemetry data were imported into ArcGIS 9.3 (ESRI) and the locations mapped with the Zone $32(\mathrm{~N})$ Universal Transverse Mercator projection, using the WGS 1984 datum.

To identify key habitats for harbor porpoises, kernel density estimation grids were produced in ArcMap V9.3 using the fixed kernel density estimator (Worton 1989) by means of Hawth's Analysis Tool V3.27 (Beyer 2004). Smoothing factor (bandwidth) was set to 20,000 and output cell size to $1 \mathrm{~km}^{2}$. This was based on thorough inspection of kernel contours during tests of alternate band-width as recommended by Beyer, the creator of Hawth's Analysis Tools. For further explanation of the chosen smoothing factor, see Appendix 3 in the online supplementary material.

The kernel density estimate is a nonparametric estimation that calculates the density distribution from a random sample of Argos locations, for example, from 
one or more satellite tagged porpoises. By determining the smallest possible area containing user-specified percentages of the locations, the kernel grid was divided into percentage volume contours from $10 \%$ to $90 \%$ in $10 \%$ intervals. For instance, the $10 \%$ volume contour consists of the smallest possible area containing $10 \%$ of the locations used to generate the original kernel density estimation grid. This means that the area within the $10 \%$ contour represents areas with highest density and the $90 \%$ contour almost the entire range of the porpoises.

The kernel density estimation tool unfortunately does not give the possibility of excluding land during the analysis. Thus, the kernel contours (especially the larger ones) will extend onto land areas and thereby mask the coastline making the distribution maps difficult to read. In order to avoid this, the kernel contours are placed underneath the land layer on all maps. As a measure for comparing porpoise distribution, a high-density area was arbitrarily defined as kernel percent volume contours of $\leq 30 \%$. The outer contour lines of the $30 \%$ polygons are highlighted on maps for illustration purposes. Area size of all kernel polygons and the proportion extending on to land were calculated.

The relative size and form of the kernel density estimation grid is dependant on the total number of locations and their distribution, that is, adding more porpoise locations to the analysis may alter the shape of the high-density areas. To challenge the validity of the high-density areas determined by the kernel density estimator, results were compared to results obtained for the same data using a grid-based method, which takes into account the inaccuracy of each Argos location and where each grid cell is independent of other grid cells and the total number of locations (Tougaard et al. 2008). Both methods identified the same high-density areas. For further explanation of the comparison, see Appendix 4 in the online supplementary material.

Variation in the distribution of porpoises was analyzed by seasons, defined as winter (December-February), spring (March-May), summer (June-August), and autumn (September-November). The unit of analysis was the individual porpoises' median latitudinal and longitudinal location, analyzed according to season in SPSS using one-way ANOVA followed by Fisher's least significant difference post hoc tests (i.e., mean median location by season). To meet assumptions of normal distribution of data and homogeneity of variance, median locations were rank transformed prior to analysis. Data from the IDW and Skagerrak groups were analyzed separately. A single porpoise from IDW displayed a different movement pattern than the rest of the group and was excluded from the analysis of seasonal movements.

Area sizes for kernel density polygons $(10 \%-90 \%)$ were calculated by age-class (immature and mature) and sex for the IDW group and the Skagerrak group, respectively.

\section{RESULTS}

\section{Satellite Telemetry}

The period of transmission from the tagged porpoises varied between 14 and $349 \mathrm{~d}$ (median $=98 \mathrm{~d}$ ) and the average number of transmissions per porpoise per active transmission day was $1.87 \pm 0.84$. The 64 porpoises were grouped according to the area in which they spend the majority of their time. The 24 porpoises tagged at Skagen (the Skagerrak group) never moved south of Anholt (Fig. 1). Of the 40 porpoises tagged in IDW, two porpoises, tagged in the northern part of the IDW, swam immediately after tagging north into Skagerrak and the North Sea and stayed 


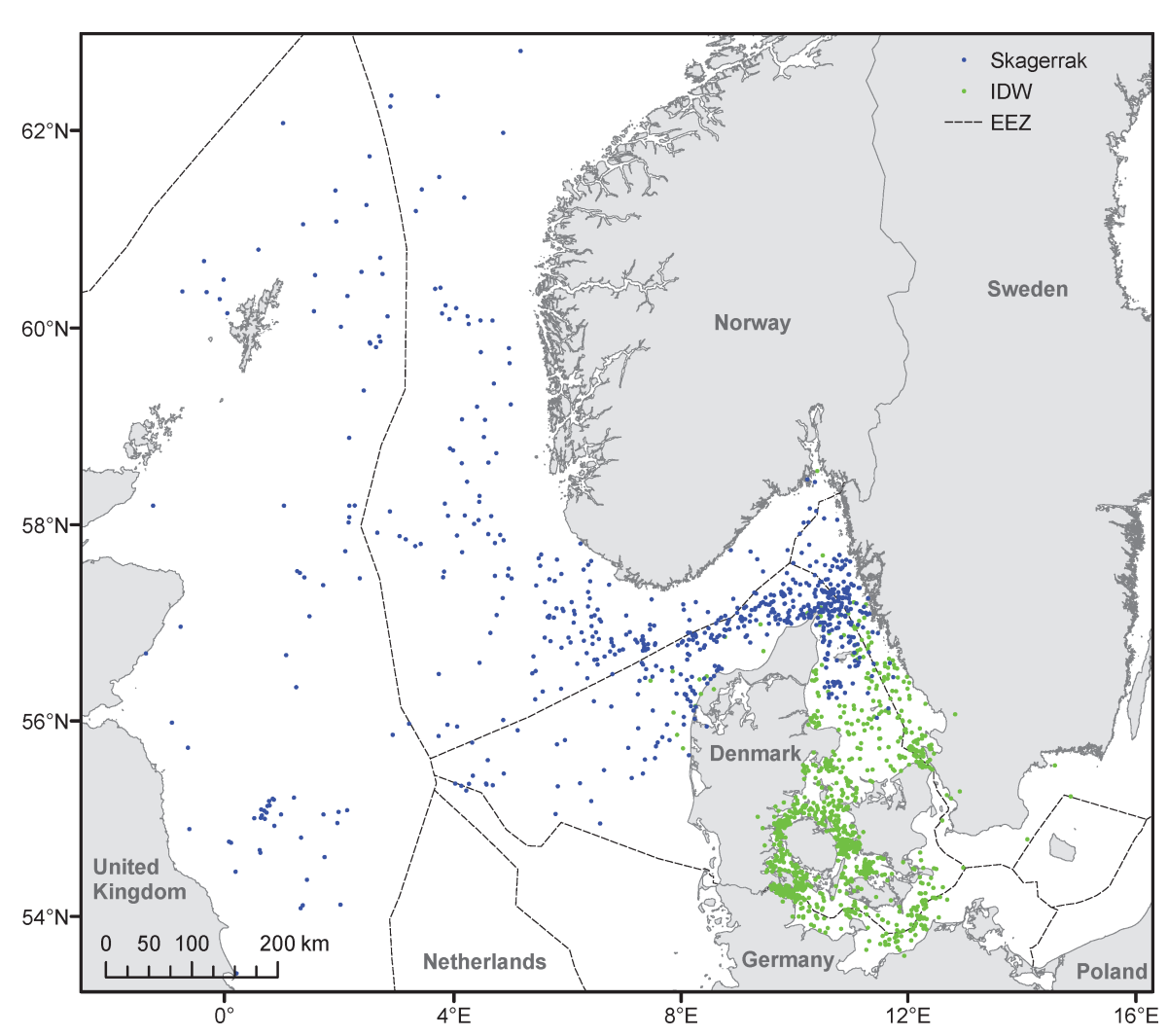

Figure 2. Locations (one per fourth day per porpoise) of the 64 harbor porpoises, Phocoena phocoena, tracked between 1997 and 2007. Locations from porpoises in the Inner Danish waters (IDW) group are green $(N=38$ porpoises, $n=933$ locations) and locations from porpoises tagged in the Skagerrak group are blue ( $N=26$ porpoises, $n=665$ locations). Map projection universal transverse Mercator, Zone 32N, WGS84. Dashed line indicates international Exclusive Economic Zones (EEZ).

there for the entire contact period. Consequently, they were considered belonging to the Skagerrak group. There was little overlap between tracks from the IDW group $(n=38)$ and the Skagerrak group $(n=26)$ (Fig. 2). Furthermore, the Skagerrak group displayed a significantly faster average swim rate $(0.85 \mathrm{~km} / \mathrm{h})$ than the IDW group $(0.64 \mathrm{~km} / \mathrm{h})$ (Student's $t$-test, $P<0.05)$. We found no significant difference in average swim rate between mature $(0.73 \mathrm{~km} / \mathrm{h})$ and immature porpoises $(0.79 \mathrm{~km} / \mathrm{h})$.

To avoid autocorrelation, only locations from every fourth day for each individual were used in the analysis. This reduced the data set by $67 \%$, but did not alter the resulting high-density areas.

\section{Distribution}

The kernel density percent volume contours of the 38 IDW porpoises and the 26 Skagerrak porpoises demonstrate that the North Sea and western Baltic is not utilized evenly by the tagged harbor porpoises (Fig. 3). The high-density areas for the entire 


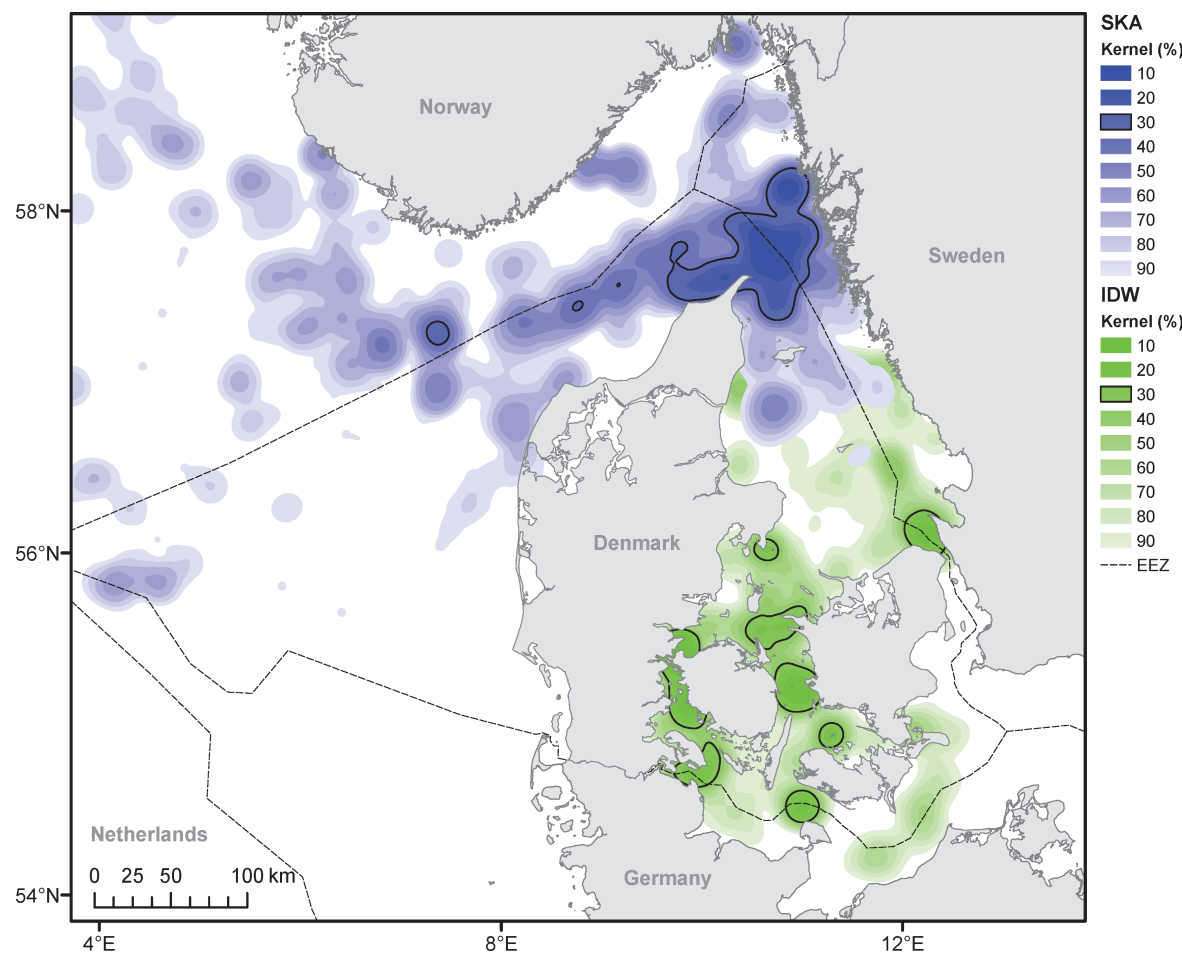

Figure 3. All year distribution of harbor porpoises Phocoena phocoena tagged between 1997 and 2007 displayed by fixed kernel density based on one location every four days from each other. The Inner Danish waters (IDW) group are shown in green ( $N=38$ porpoises, $n=$ 950 locations) and the Skagerrak group (SKA) are shown in blue ( $N=26$ porpoises, $n=$ 665 locations). Black line indicates high-density areas defined as the $30 \%$ kernel contour. Projections as in Figure 2. Dashed line indicates international Exclusive Economic Zones (EEZ). Kernel layers are placed below the land layer.

year, defined as kernel density contours $\leq 30 \%$, were found to be northern Øresund, northern Sams $\varnothing$ Belt, Kalundborg Fjord, Little Belt, Great Belt, Smålandshavet, Flensborg Fjord, and Fehmarn Belt for the IDW group and a large area at the border between northern Kattegat and the southeastern Skagerrak (hereafter called the tip of Jylland) as well as three smaller areas along the Norwegian trench for the Skagerrak group (see Fig. 1, 3).

Proportion of land for each kernel percentage contour within the Skagerrak and the IDW group were similar but varied greatly between the two groups. In the IDW group, the percentage of land within each kernel was $22 \%-30 \%$ and for the Skagerrak group 1\%-3\% (see Fig. 4). This difference is due to the morphology of the IDW with many island and belts $v$ s. Skagerrak and the North Sea with much larger open oceans.

In spring and summer (the reproductive period), the Skagerrak porpoises stay close to the tip of Jylland while the IDW animals spread out in the entire range of their distribution (Fig. 5). The high-density areas for the spring and summer are the tip of Jylland, Store Middelgrund, northern Øresund, southern Samsø Belt, Smålandshavet, 


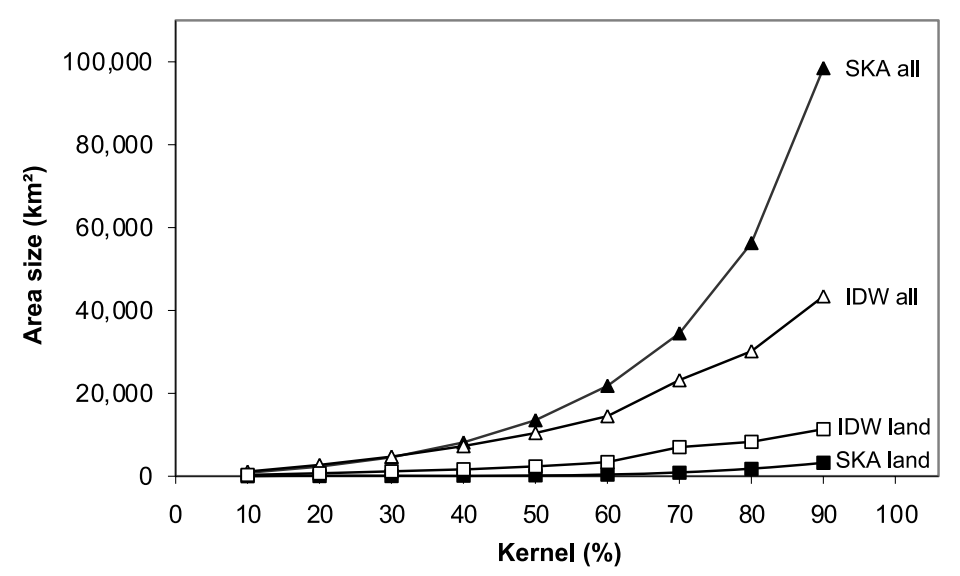

Figure 4. Area size of each kernel density contour and the area comprising land within each kernel for Inner Danish Waters (IDW) $(N=38$ porpoises) and the Skagerrak group (SKA) ( $N=26$ porpoises).

Little Belt, Flensborg Fjord, Great Belt, and Fehmarn Belt (Fig. 1). In autumn and winter the distribution is somewhat different, with the Skagerrak porpoises moving further west into the northeastern North Sea (although high porpoise density still remains in Skagerrak) and the IDW porpoises moving south avoiding the Kattegat area. The main high-density areas for autumn and winter are the tip of Jylland, an area along the slope to the deep Norwegian Trench, the southern Little Belt, Flensborg Fjord, Great Belt, Kalundborg Fjord, Fehmarn Belt, and the Cadet Trench.

Based on median location as the unit of analysis, the central tendency (mean of medians) in these locations differed significantly between seasons. Whereas the IDW population shows no seasonal variation in longitudinal locations (one-way ANOVA, $F_{3,75}=0.07, P=0.98$ ), the southward movements from spring to winter is significant (one-way ANOVA, $F_{3,75}=2.85, P=0.043$; significant post boc tests: spring-autumn and spring-winter, $P=0.030$ ) (Fig. 6). In contrast, the Skagerrak (SKA) shows no overall latitudinal movements during the course of the year (one-way ANOVA, $\left.F_{3,57}=0.15, P=0.93\right)$, whereas the longitudinal westward movements into the North Sea from spring to winter is statistically significant (one-way ANOVA, $F_{3,57}=3.42, P=0.023$; significant post hoc tests: spring-winter and summer-winter, $P \leq 0.026$ ) (Fig. 6).

The combined home range, that is, the kernel density percentage contours (10\%$90 \%$ ), of the immature porpoises for the IDW and the Skagerrak group, was larger than the mature porpoises (Fig. 7) with immature home range being up to four times larger than the mature home ranges for the Skagerrak group and up to two times larger for the IDW group. Males and females within the IDW group showed no difference in home range size, but males in the Skagerrak group had larger home ranges than females. This may be attributed to the low number of female porpoises tagged in Skagerrak in comparison to males.

\section{DISCUSSION}

Our data provide new insight to the distribution patterns of harbor porpoises from the North Sea to the western Baltic Sea and intermediate waters. High-density 

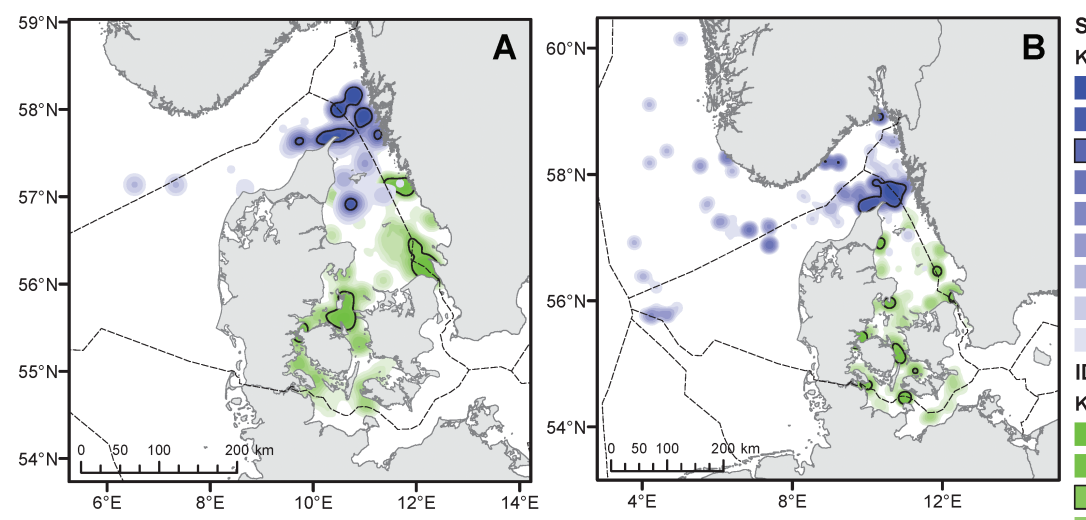

SKA group

Kernel (\%)

10
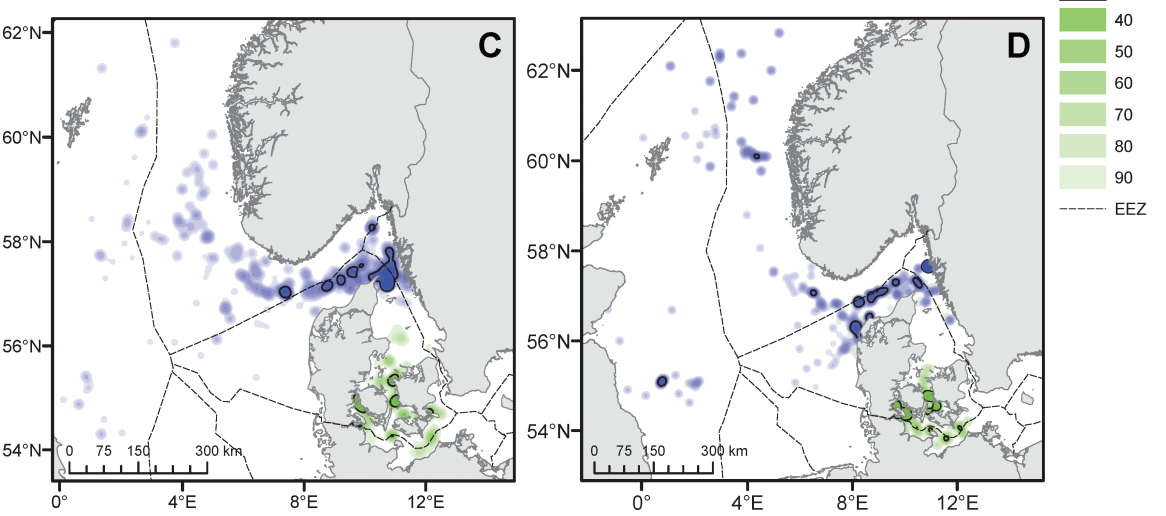

Figure 5. Seasonal distribution for harbor porpoises Phocoena phocoena tagged in the Inner Danish Waters (IDW) population (green) and in Skagerrak (blue) displayed by fixed kernel density estimations based on one location every four days from each other. Black line indicates high-density areas defined as the $30 \%$ kernel contour. (A) spring (IDW: $N=29, n=268$; Skagerrak: $N=12, n=103$ ), (B) summer (IDW: $N=27, n=353$; Skagerrak: $N=18, n=$ 155), (C) autumn (IDW: $N=17, n=210$; Skagerrak: $N=19, n=250$ ) and (D) winter (IDW: $N=8, n=119$; Skagerrak: $N=12, n=157$ ). Projections as in Figure 2. Dashed line indicates international Exclusive Economic Zones (EEZ). Kernel layers are placed below the land layer.

areas were clearly identified and thus, harbor porpoises do not distribute evenly, but aggregate in certain areas, that is, key habitats. The 64 individual tracks were used to identify nine high-density areas for harbor porpoises using weighted kernel density estimation. The two porpoise groups showed very little overlap in distribution and may belong to each of the two porpoise populations (one in the Kattegat, Belt Sea, and the western Baltic and one in Skagerrak and the North Sea) indicated previously by genetic methods (Andersen et al. 2001).

Four of the high-density areas found by satellite tracking are supported by previous studies using other methods. For instance, Heide-Jørgensen et al. (1993) conducted aerial surveys in the waters north of Fyn, Great Belt, and the Kiel Bay and found that the density in Great Belt was more than twice that of the other areas. The highest density of harbor porpoises ever reported in Europe was also found in the Great Belt 


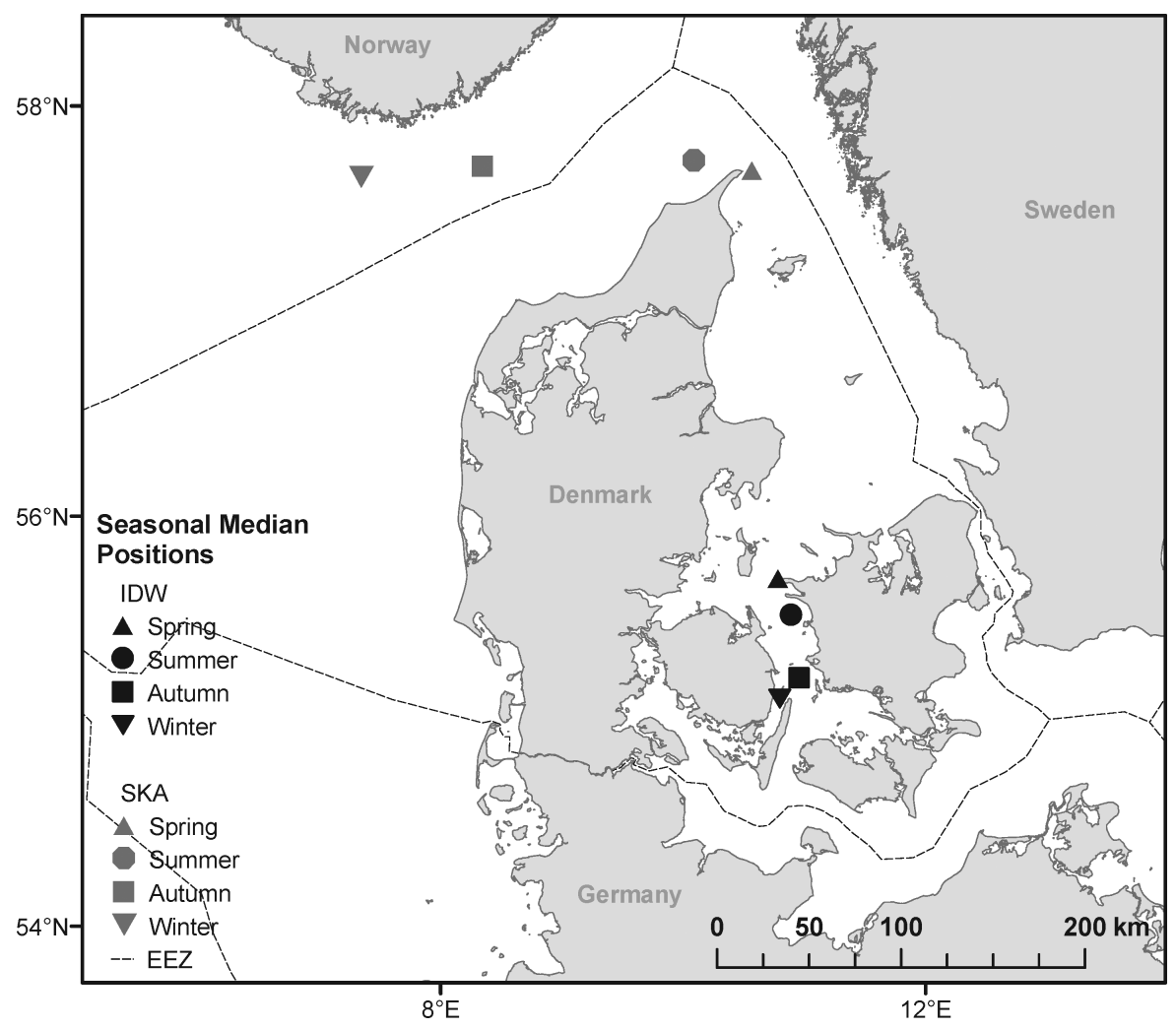

Figure 6. Mean locations of median seasonal distribution of harbor porpoises Phocoena phocoena (spring, summer, autumn, winter) for porpoises tagged in the Inner Danish Waters (IDW) (black) and in Skagerrak (SKA) (light gray). Spring (IDW: $N=29$ porpoises; Skagerrak: $N=12$ porpoises), summer (IDW: $N=27$; Skagerrak: $N=18$ ), autumn (IDW: $N=$ 17; Skagerrak: $N=19$ ) and winter (IDW: $N=8$; Skagerrak: $N=12$ ). Dashed line indicates international Exclusive Economic Zones (EEZ).

during spring from a ship survey (Teilmann 2003). Visual and acoustic surveys in the western Baltic indicated an increase in porpoises from east to west with particularly high porpoise density in Flensborg Fjord and in Little Belt and almost no porpoises in the Baltic proper (Gillespie et al. 2005). Verfuss et al. (2007) deployed acoustic data loggers (T-PODs) along the German Baltic coastline and found Fehmarn Belt to have the highest intensity of porpoise echolocation. Thus, entirely different methods have confirmed the presence of half of the high-density areas identified by satellite tracking in our study. Therefore, we find that kernel- and grid-based analysis of satellite tracking are valid methods for identifying high density areas for harbor porpoises.

Our study suggests a seasonal change in importance of some of the high-density areas. From spring/summer to autumn/winter, the porpoises in IDW and Skagerrak moved south and west, respectively. This shift does not seem to be a coordinated migration, but rather a gradual overall movement over a longer period. Our findings correlate with the results of Read and Westgate (1997), who satellite tracked nine harbor porpoises in the Bay of Fundy and Gulf of Maine, Canada, and found seasonal 


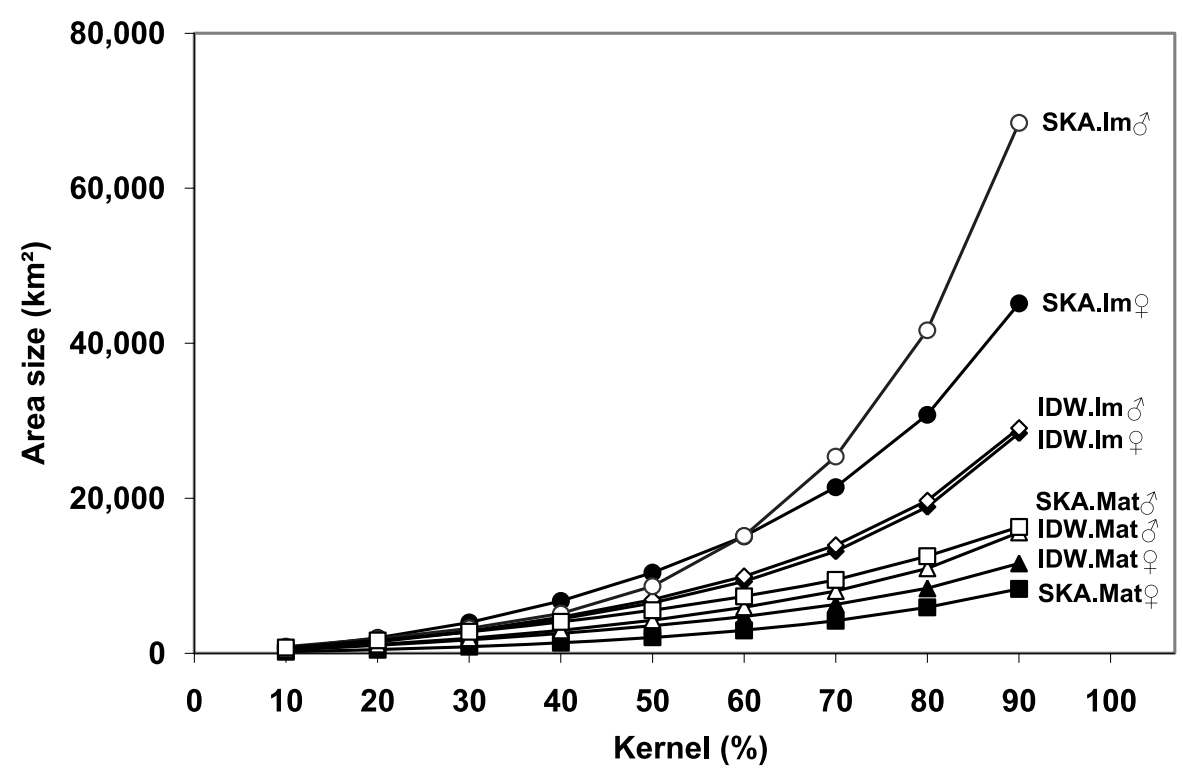

Figure 7. Area size of each kernel density contour divided by into groups by sex [females (ㅇ), males $\left(\sigma^{7}\right)$ ], and age-class [immature (Im), mature (Mat)] for the two harbor porpoise groups; Inner Danish waters (IDW) and Skagerrak (SKA). Number of porpoises in each category in IDW were: mature $\mathrm{F}=5$, mature $\mathrm{M}=7$, immature $\mathrm{F}=11$, immature $\mathrm{M}=15$ and in Skagerrak (mature $\mathrm{F}=1$, mature $\mathrm{M}=5$, immature $\mathrm{F}=6$, immature $\mathrm{M}=14$ ).

changes in distribution to exist, but they were individually discrete and gradual. Seasonal changes in density patterns of small cetaceans have also been observed in other cetaceans, for example, bottlenose dolphins (Tursiops truncates) in the Moray Firth, Scotland (Wilson et al. 1997). The seasonal movements may be linked to changes in distribution of prey (Gaskin 1982). Our study is the first to identify a specific seasonal trend for harbor porpoises on a large scale. In fact, very little other information is available to describe the harbor porpoise distribution in the study area during the winter season, because visual surveys are difficult to conduct due to poor weather conditions and reduced number of daylight hours.

Home range size of immature porpoises was found to be considerably larger than the mature porpoises for both the IDW and the Skagerrak group. The home range of mature porpoises is comparable in both groups, but the immature porpoises in the Skagerrak group are almost twice the size of the immature porpoises in the IDW group. The difference is clearly illustrated by the fact that none of the mature porpoises moved further west than $6^{\circ} \mathrm{E}$, and so only immature porpoises move north along the coast of Norway and west to the coast of the United Kingdom $\left(3^{\circ} \mathrm{W}\right)$. This may indicate that immature and thus inexperienced porpoises have to move larger distances in order to locate prey than mature individuals or that they are less settled to a specific area. The Skagerrak porpoises move approximately $30 \%$ faster than the IDW group, which may be needed to swim the longer distances. However, it may be a consequence of the larger home ranges, which causes the distance between two satellite-logged locations to be further apart, incorrectly indicating a higher swim rate, that is, if the IDW animals swim just as fast but in circling movements, the speed measured between two locations will be slower. 
No difference was found in home range size in relation to sex within the two maturity groups for the IDW group. For the Skagerrak group, both the immature and the mature males appear to have larger home range than the immature and the mature females, respectively, but this may be the result of unbalanced sample size.

The results in this study are based on the assumption that the 64 tagged harbor porpoises are representative for the general behavior of porpoises in the study area. Although the presence of high-density areas is confirmed by other methods, animals should preferably be tagged randomly throughout the study area and represent a natural distribution of sex and age classes. This is rarely possible and in this study tagging sites were restricted to the coastal regions where the pound net fishery is carried out. The age structure for wild-living harbor porpoises is unknown. Information derives from stranded or bycaught porpoises that may be biased. Strandings may contain a high proportion of naturally dead animals and bycaught individuals may represent lack of experience leading to higher probability of capture. However, except for only having tagged a single mature female in the Skagerrak group, the sex and age distribution in this study is comparable to findings in studies on bycaught (Read and Hohn 1995) and stranded harbor porpoises (Benke et al. 1998, Siebert et al. 2006, Jung et al. 2009).

Satellite telemetry provides presence-only data, that is, we do not know whether further tagging of porpoises would reveal new key habitats. Still, the study represents the most comprehensive satellite tagging program for any cetacean within the same region. Satellite tracking combines temporal and spatial information on a broader scale and provides unique continuous information on individual behavior as well as on a general population level unlike any other method.

The harbor porpoise is a wide-ranging species with a large home range (Read and Westgate 1997), and thus has the ability to occupy/exploit any site within the study area. Hence, the fact that (1) some areas are preferred to others, (2) that some of these areas (e.g., northern Øresund) are relatively far away from the tagging sites, and (3) that porpoises often spend time in several of the identified key habitats, suggest that the presently identified key areas are relatively independent of tagging site within the range of each population.

An important prerequisite for fixed MPAs is that the key habitats do not vary greatly from year to year. This study was conducted over a 10-yr period required to catch and tag the presented number of porpoises. Compiling data over several years may hide temporal trends in spatial distribution, but inspection of the individual tracks does not suggest this to be the case. A time-trend study based on, for example, regular acoustic surveys throughout the year and the deployment of T-PODs in and adjacent to the identified key habitats, could further examine such seasonal and year-to-year changes.

Finally, this study provides information on high-density areas, which were not previously known, and the areas are identified with a resolution in time and space appropriate for use in area protection and other management. In the EU, all relevant member states are legally obliged to protect the harbor porpoise by designating SAC according to the EC Habitat Directive (92/43/EEC 1992). It is clear from this study, that international cooperation is essential in the designation of these protected areas. The harbor porpoise is a wide-ranging species and the tagged individuals utilized Danish, Norwegian, Swedish, German, and British waters and several high-density areas are divided between countries. During the process of identifying SAC for harbor porpoises in Denmark, the Danish authorities have based their selection of protected areas mainly on the data presented in this paper. Two of these areas, Flensborg Fjord and Fehmern Belt, adjoin German designated SAC for harbor porpoises. The 
EC Habitat Directive thus provides a legal forum for designating large coherent protected areas across national borders in Europe, which is required in order to protect the harbor porpoise in their key habitats.

This study arbitrarily defined high-density areas as $\leq 30 \%$ kernel polygons for illustrative purposes and it should be noted that this exact limit is not scientifically supported to be used for management purposes.

\section{ACKNOWLEDGMENTS}

Fifty-one of the 64 tagged porpoises were tagged as part of a joint project between the Danish Institute for Fisheries Research, the Fjord and Belt Centre, NERI, and University of Southern Denmark in the years 1997-2002. The remaining 13 porpoises were tagged as part of cooperation between NERI and University of Kiel, Research and Technology Centre (FTZ) in 2003-2007. The study was carried out under permissions from Danish Forest and Nature Agency (SN 343/SN-0008) and the Animal Welfare Division (Ministry of Justice, 1995101-62). The Danish Forest and Nature Agency and the University of Southern Denmark, Odense, are thanked for financial support. The collaboration with the Danish fishermen and a large number of volunteers is greatly acknowledged, without their contributions the study would not have been possible. Finally, we wish to thank the two anonymous reviewers, whose comments and suggestions greatly improved the paper.

\section{Literature Cited}

92/43/EEC. 1992. EC habitats directive. Council Directive 92/43/EEC of 21 May 1992 on the conservation of natural habitats and of wild fauna and flora. Available at http://eurlex.europa.eu/LexUriServ/LexUriServ.do? uri=CONSLEG:1992L0043:20070101:EN: PDF.

Aebischer, N. J., P. A. Robertson and R. E. Kenward. 1993. Compositional analysis of habitat use from animal radio-tracking data. Ecology 74:1313-1325.

Andersen, L. W., D. E. Ruzzante, M. Walton, P. Berggren, A. Bjørge and C. Lockyer. 2001. Conservation genetics of harbour porpoises, Phocoena phocoena, in eastern and central North Atlantic. Conservation Genetics 2:309-324.

Anonymous. 2006. Small cetaceans in the European Atlantic and North Sea (SCANS-II). LIFE Project No. LIFE04NAT/GB/000245. University of St Andrews, Fife, Scotland, UK. Available at http://biology.st-and.ac.uk/scans2/inner-finalReport.html.

Benke, H., U. Siebert, R. Lick, B. Bandomir and R. Weiss. 1998. The current status of harbour porpoises (Phocoena phocoena) in German waters. Archive of Fishery and Marine Research 46:97-123.

Beyer, H. L. 2004. Hawth's analysis tools for ArcGIS. Available at http://www. spatialecology.com/htools/.

Carstensen, J., O. D. Henriksen and J. Teilmann. 2006. Impacts of offshore wind farm construction on harbour porpoises: Acoustic monitoring of echolocation activity using porpoise detectors (T-PODs). Marine Ecology-Progress Series 321:295-308.

Crawley, M. J. 2002. Statistical computing: An introduction to data analysis using S-Plus. Wiley, West Sussex, UK.

Douglas, D. 2006. The Douglas Argos-filter algorithm, Version 7.03. U.S. Geological Survey, Anchorage, AK. Available at http://alaska.usgs.gov/science/biology/spatial/ pdfs/argosfilterv703_manual.pdf.

Edrén, S. M. C., M. S. Wisz, J. Teilmann, R. Dietz and J. Söderkvist. In press. Modelling spatial patterns in harbour porpoise satellite telemetry data using maximum entropy. Ecography.

Eskesen, I. G., J. Teilmann, B. M. Geertsen, G. Desportes, F. Riget, R. Dietz, F. Larsen and U. Siebert. 2009. Stress level in wild harbour porpoises (Phocoena phocoena) during 
satellite tagging measured by respiration, heart rate and cortisol. Journal of the Marine Biological Association of the United Kingdom 89:885-892.

European Commission. 2007. Guidelines for the establishment of the Natura 2000 network in the marine environment. Application of the Habitats and Birds Directives. Available at http://ec.europa.eu/environment/nature/natura2000/marine/docs/marine_guidelines.pdf

Fieberg, J. 2007. Utilization distribution estimation using weighted kernel density estimators. Journal of Wildlife Management 71:1669-1675.

Freitas, C., C. Lydersen, M. A. Fedak and K. M. Kovacs. 2008. A simple new algorithm to filter marine mammal Argos locations. Marine Mammal Science 24:315-325.

Gaskin, D. E. 1982. The ecology of whales and dolphins. Heinemann, London, UK.

Geertsen, B. M., J. Teilmann, R. A. Kastelein, H. N. J. Vlemmix and L. A. Miller. 2004. Behaviour and physiological effects of transmitter attachments on a captive harbour porpoise (Phocoena phocoena). Journal of Cetacean Research and Management 6:139146.

Gillespie, D., P. Berggren, S. Brown, I. Kuklik, C. Lacey, T. Lewis, J. Matthews, R. McLanaghan, A. Moscrop and N. Tregenza. 2005. Relative abundance of harbour porpoise (Phocoena phocoena) from acoustic and visual surveys of the Baltic and adjacent waters during 2001 and 2002. Journal of Cetacean Research and Management 7:51-57.

Hammond, P. S., P. Berggren, H. Benke, D. L. Borchers, A. Collet, M. P. Heide-Jorgensen, S. Heimlich, A. R. Hiby, M. F. Leopold and N. Oien. 2002. Abundance of harbour porpoise and other cetaceans in the North Sea and adjacent waters. Journal of Applied Ecology 39:361-376.

Heide-Jørgensen, M. P., A. Mosbech, J. Teilmann, H. Benke and W. Schultz. 1992. Harbor porpoise (Phocoena phocoena) densities obtained from aerial surveys north of Fyn and in the Bay of Kiel. Ophelia 35:133-146.

Heide-Jørgensen, M. P., J. Teilmann, H. Benke and J. Wulf. 1993. Abundance and distribution of harbor porpoises Phocoena phocoena in selected areas of the western Baltic and the North Sea. Helgolander Meeresuntersuchungen 47:335-346.

Hoyt, E. 2005. Marine protected areas for whales, dolphins and porpoises: A world handbook for cetacean habitat conservation. Earthscan Publications, London, UK.

Jung, J. L., E. Stephan, M. Louis, E. Alfonsi, C. Liret, F. G. Carpentier and S. Hassani. 2009. Harbour porpoises (Phocoena phocoena) in north-western France: Aerial survey, opportunistic sightings and strandings monitoring. Journal of the Marine Biological Association of the United Kingdom 89:1045-1050.

Lockyer, C., and K. Kinze. 2003. Status, ecology and life history of harbour porpoise (Phocoena phocoena), in Danish Waters. NAMMCO Scientific Publication 5:143-176.

Read, A. J., and A. A. Hohn. 1995. Life in the fast lane-the life-history of harbor porpoises from the Gulf of Maine. Marine Mammal Science 11:423-440.

Read, A. J., and A. J. Westgate. 1997. Monitoring the movements of harbour porpoises (Phocoena phocoena) with satellite telemetry. Marine Biology 130:315-322.

Reijnders, P. 1992. Harbour porpoises Phocoena phocoena in the North Sea: Numerical responses to changes in environmental conditions. Netherlands Journal of Aquatic Ecology 26:7585.

Rooney, S. M., A. Wolfe and T. J. Hayden. 1998. Autocorrelated data in telemetry studies: Time to independence and the problem of behavioural effects. Mammal Review 28:8998.

Scheidat, M., K. Kock and U. Siebert. 2004. Summer distribution of harbour porpoise (Phocoena phocoena) in the German North Sea and the Baltic Sea. Journal of Cetacean Research and Management 6:251-257.

Siebert, U., A. Gilles, K. Lucke, M. Ludwig, H. Benke, K. H. Kock and M. Scheidat. 2006. A decade of harbour porpoise occurrence in German waters-analyses of aerial surveys, incidental sightings and strandings. Journal of Sea Research 56:65-80.

Teilmann, J. 2000. The behaviour and sensory abilities of harbour porpoises (Phocoena phocoena) in relation to bycatch in gillnet fishery. Ph.D. thesis, University of Southern Denmark, Odense, Denmark. 219 pp. 
Teilmann, J. 2003. Influence of sea state on density estimates of harbour porpoise (Phocoena phocoena). Journal of Cetacean Management 5:85-92.

Teilmann, J., F. Larsen and G. Desportes. 2007. Time allocation and diving behaviour of harbour porpoises (Phocoena phocoena) in Danish and adjacent waters. Journal of Cetacean Management 9:201-210.

Teilmann, J., S. Sveegaard, R. Dietz, I. K. Petersen, P. Berggren and G. Desportes. 2008. High density areas for harbour porpoises in Danish waters. National Environmental Research Institute, Aarhus University. NERI Tecnical Report No. 657. $84 \mathrm{pp}$.

Tougaard, J., J. Teilmann and S. Tougaard. 2008. Harbour seal spatial distribution estimated from Argos satellite telemetry-overcoming positioning errors. Endangered Species Research 4:113-122.

Verfuss, U. K., C. G. Honnef, A. Meding, M. Dahne, R. Mundry and H. Benke. 2007. Geographical and seasonal variation of harbour porpoise (Phocoena phocoena) presence in the German Baltic Sea revealed by passive acoustic monitoring. Journal of the Marine Biological Association of the United Kingdom 87:165-176.

Vincent, C., B. J. McConnell, V. Ridoux and M. A. Fedak. 2002. Assessment of Argos location accuracy from satellite tags deployed on captive gray seals. Marine Mammal Science 18:156-166.

Vinther, M., and F. Larsen. 2004. Updated estimates of harbour porpoise (Phocoena phocoena) bycatch in the Danish North Sea bottom-set gillnet fishery. Journal of Cetacean Research and Management 6:19-24.

Wilson, B., P. M. Thompson and P. S. Hammond. 1997. Habitat use by bottlenose dolphins: Seasonal distribution and stratified movement patterns in the Moray Firth, Scotland. Journal of Applied Ecology 34:1365-1374.

Worton, B. J. 1989. Kernel methods for estimating the utilization distribution in home-range studies. Ecology 70:164-168.

Received: 12 June 2009

Accepted: 18 December 2009

\section{SUPPORTING INFORMATION}

The following supporting information is available for this article online:

Appendix S1: Filtering of Argos locations.

Appendix $S 2$ : Weighing number of locations by porpoise.

Appendix S3: Choice of smoothing factor (band-width).

Appendix S4: Global vs. local estimates of density.

Figure S1: Track of two harbor porpoises before (left panels) and after applying Distance-Angle-Rate filter to the original Argos data.

Figure S2: Kernel distribution of porpoises tagged in the Danish waters between 1997 and 2007 for all year round ( $N=64$ porpoises, $n=4,309$ locations).

Figure S3: Comparison of smoothing factor used in Kernel density estimation of utilization distribution.

Figure S4: Distribution of porpoises tagged in Danish waters between 1997 and 2007 ( $N=64$ porpoises, $n=4,309$ locations).

Figure S5: Correlation between the kernel density estimation and the grid analysis.

Table S1: Number of Argos locations of various location classes in the harbor porpoise dataset (64 porpoises) and the percentage of locations removed from the dataset by the Distance-Angle-Rate filter: (1) including all locations that passed the filtering algorithm and (2) one location per day. 


\section{THIS DOCUMENT CONTAINS SUPPORTING INFORMATION FOR:}

Sveegaard, S., J. Teilmann, J. Tougaard, R. Dietz, K. N. Mouritsen, G. Desportes and U. Siebert. 2010. High-density areas for harbor porpoises (Phocoena phocoena) identified by satellite tracking. Marine Mammal Science.

\section{APPENDIX 1. FILTERING OF ARGOS LOCATIONS}

To remove unrealistic Argos locations, the locations were filtered by a SAS-routine, Argos Filter v7.03 (Douglas 2006). This so called DAR (Distance-Angle-Rate) filter attempts to identify implausible locations based on the fact that most suspicious Argos locations cause an animal to incorrectly move a substantial distance and then return, resulting in a tracking-path that goes 'out-and-back' (and/or further validated by unrealistic movement rates, depend- ing on the temporal frequency of the locations). The entire DAR filtering strategy is iterated 3 times, each successive iteration using only locations that passed the previous iteration. It is necessary to iterate the DAR strategy multiple times because filtering a location during one iteration may create implausible rates of movements or suspicious angles that need to be reevaluated by a subsequent iteration.
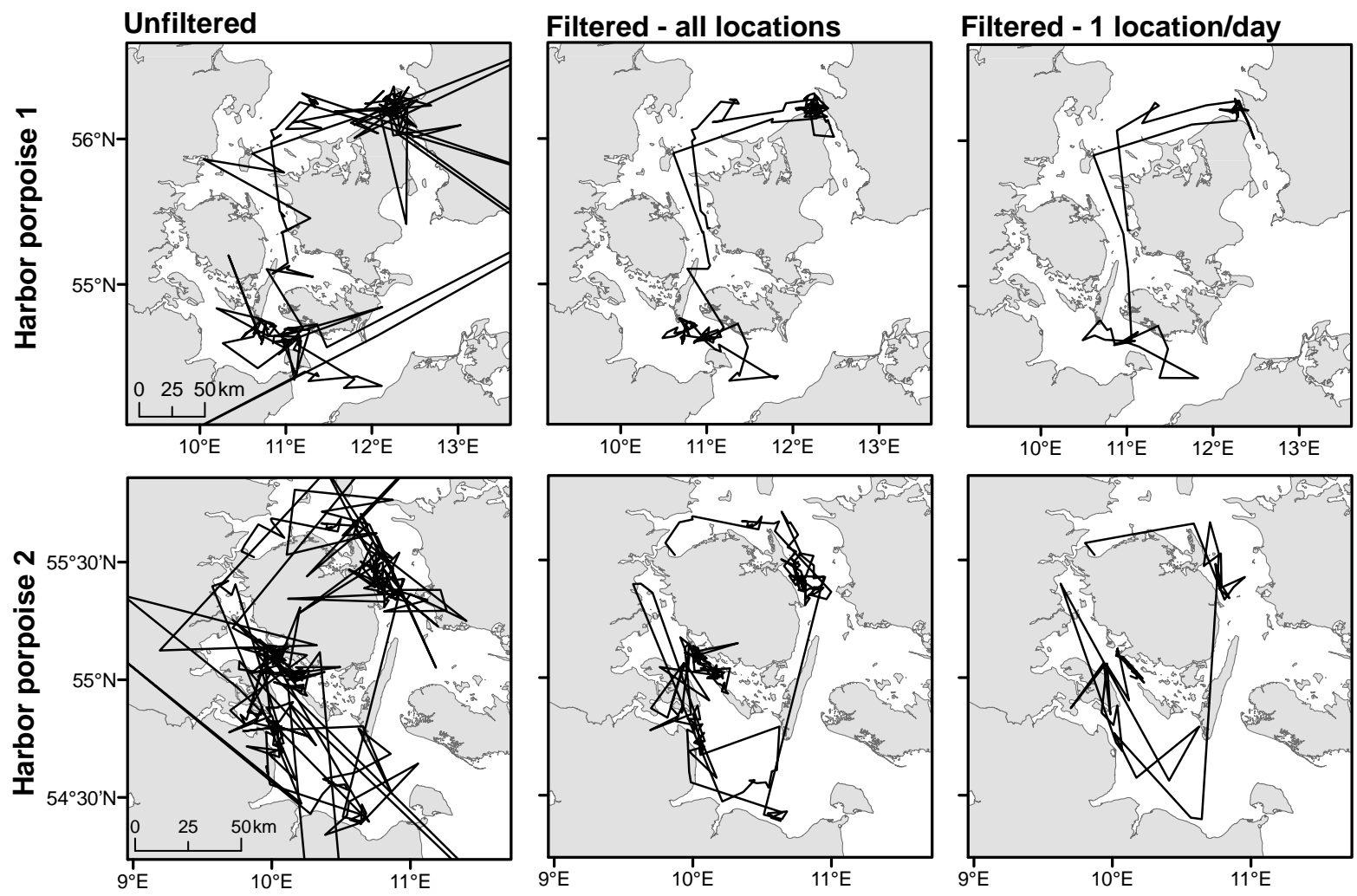

Figure s1. Track of two harbor porpoises before (left panels) and after applying DAR-filter to the original Argos data. All Argos locations that passed the DAR-filter are shown in the centre panels and the best Argos location per porpoise per day that passed the DAR-filter in the right panels. Map projection universal transverse Mercator, Zone 32N, WGS84. 
Figure S1 shows tracks of two harbor porpoises tracked in this study before and after applying the DAR-filter to the original Argos data. The DAR filter removes the improbable locations and creates a plausible track with few locations on land. The DAR filter removed $34 \%$ of the original Argos locations when including all locations that passed the DAR-filtering algorithm and $77 \%$ when only including the best (most precise) location for each porpoise per day (Table S1). The $34 \%$ is comparable to the findings of Freitas et al. (2008). They tested on 67 tracks from 9 different marine mammal species and found that their SDA-filter (SpeedDistance-Angle) removed 26-50 \% of all locations. They did not test for one location per day. However, Figure S1 clearly shows that when only selecting the best location per day of the locations that passed the DAR-filter, the track becomes very plausible with only few or no locations on land.

Table S1. Number of Argos locations of various location classes in the harbor porpoise dataset (64 porpoises) and the percentage of locations removed from the dataset by the DAR filter 1) including all locations that passed the filtering algorithm and 2) one location per day.

\begin{tabular}{|c|c|c|c|c|c|}
\hline $\begin{array}{r}\text { Location } \\
\text { Class }\end{array}$ & No filter & $\begin{array}{l}\text { 1. DAR-filter } \\
\text { all locations }\end{array}$ & $\begin{array}{l}6 \text { removed } \\
\text { using } 1 .\end{array}$ & $\begin{array}{l}\text { 2. DAR-filter } \\
1 \text { location/day }\end{array}$ & $\begin{array}{c}\text { removed } \\
\text { using } 2 .\end{array}$ \\
\hline 3 & 307 & 307 & 0 & 281 & 8 \\
\hline 2 & 894 & 791 & 12 & 555 & 38 \\
\hline 1 & 2419 & 2009 & 17 & 1055 & 56 \\
\hline 0 & 4175 & 2684 & 36 & 1081 & 74 \\
\hline A & 4729 & 3111 & 34 & 858 & 82 \\
\hline B & 7179 & 4132 & 42 & 651 & 91 \\
\hline Total & 19703 & 13034 & 34 & 4481 & 77 \\
\hline
\end{tabular}

\section{APPENDIX 2. WEIGHING NUMBER OF LOCATIONS BY PORPOISE}

To account for the variation in transmission longevity among porpoises, kernel density estimation with equal weight on each porpoise was used in all analysis in the paper. The weight of each location was thus calculated as:

Weight of each location (Porpoise $X)=$ $1 /$ total number of transmission days for porpoise $X$

This weighting introduces a bias towards animals with short transmitter lifetime. In order to evaluate the magnitude of the bias it was compared to an alternative kernel den- sity estimation with equal weight on each location. This will bias the analysis towards animals with longer transmitter life.

To compare the two methods of weighting data, the study area was divided into grid cells of $4 \times 4 \mathrm{~km}$. Each cell was assigned the value of the underlying kernel density surface sampled at the centre of the cell. The two grids of weighted locations and weighted animals, respectively, can be seen in Fig. S2.

The satellite transmitters on the 64 porpoises had variable lifetime (from 14 to 349 days) and as a consequence the two different method of weighing data could produce sig- 


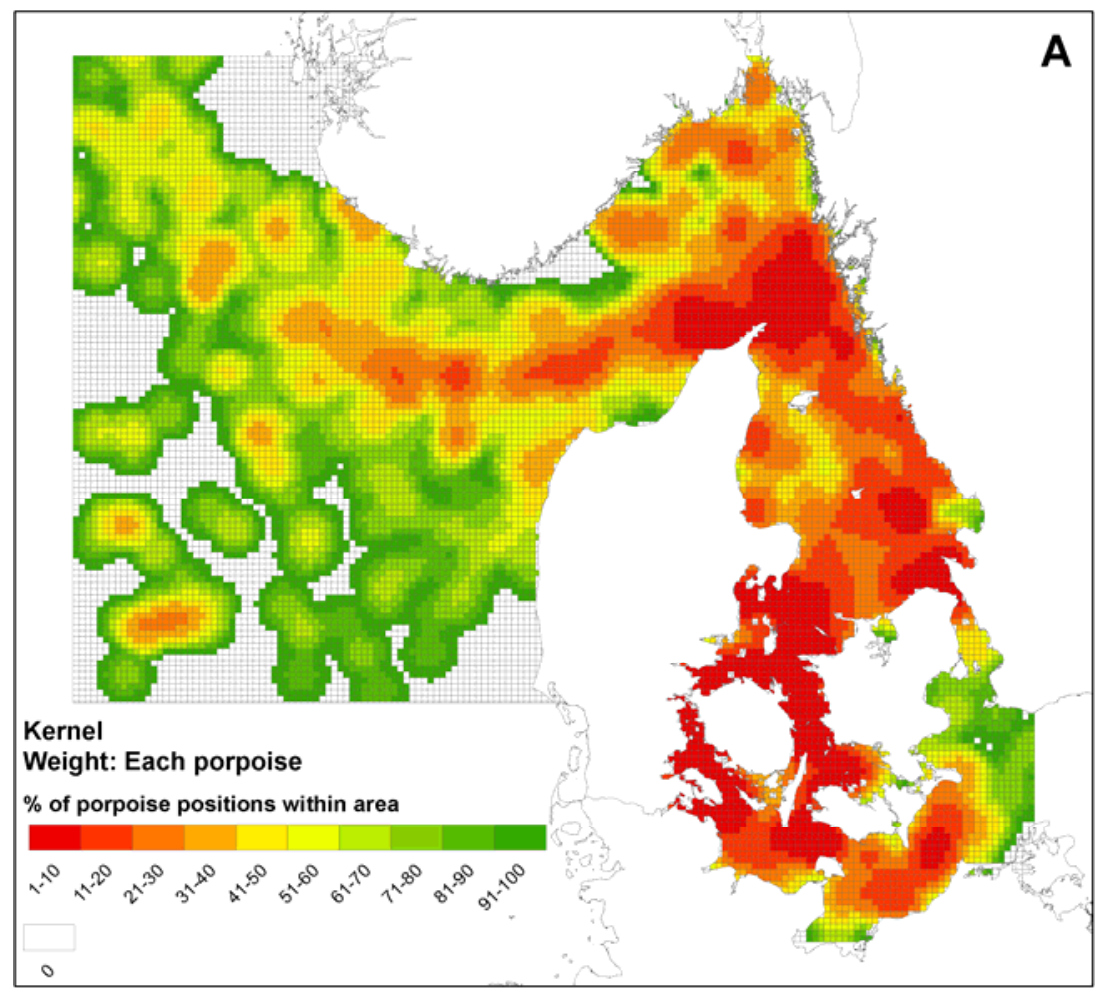

nificantly different distribution maps. However, we find that the high density areas are selected in both distribution maps although the shapes are somewhat different. A high correlation coefficient $\left(\mathrm{R}^{2}=0.84\right)$ was found when correlating the two methods cell by cell. The dataset therefore seem robust to transmitter longevity and weighting for the purpose of identifying high density areas.

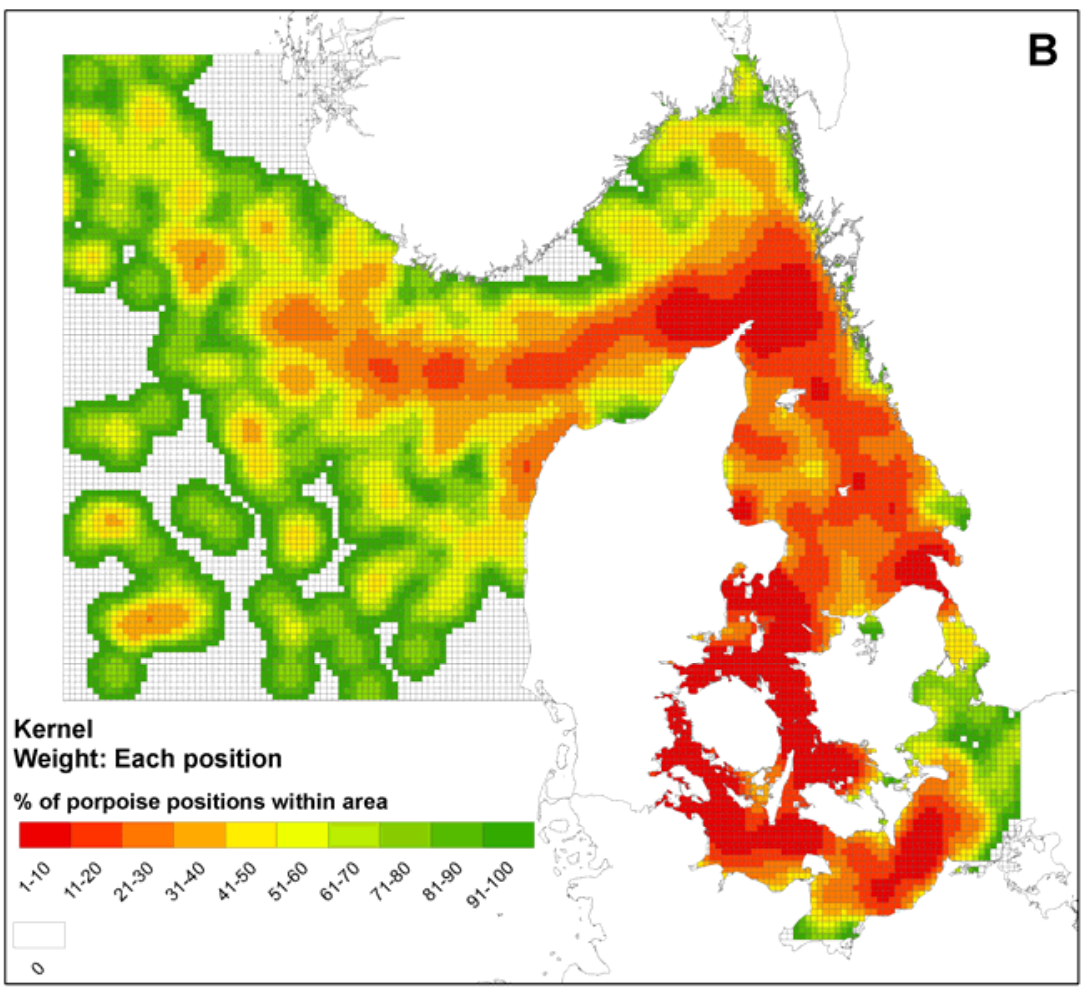

Figure S2. Kernel distribution of porpoises tagged in the Danish waters between 1997 and 2007 for all year round ( $N=64$ porpoises, $n=4309$ locations). Comparison of methods of weighting kernel data: $A$ ) weight on each porpoise and $B$ ) weight on each location. Map projection universal transverse Mercator, Zone 32N. 


\section{APPENDIX 3. CHOISE OF SMOOTHING FACTOR (BAND WIDTH)}

The impact of smoothing factor on the results of the kernel density estimations have been widely studied, although no congruence of best practice has been established (Worton 1989, Blundell et al. 2001). We evaluated the effects of smoothing on kernel estimates for harbor porpoises in this study by calculating the Kernel density estimates for the IDW group (38 harbor porpoises) using three different band widths: 10,000, 20,000 and 30,000 (Fig. S3). While 10,000
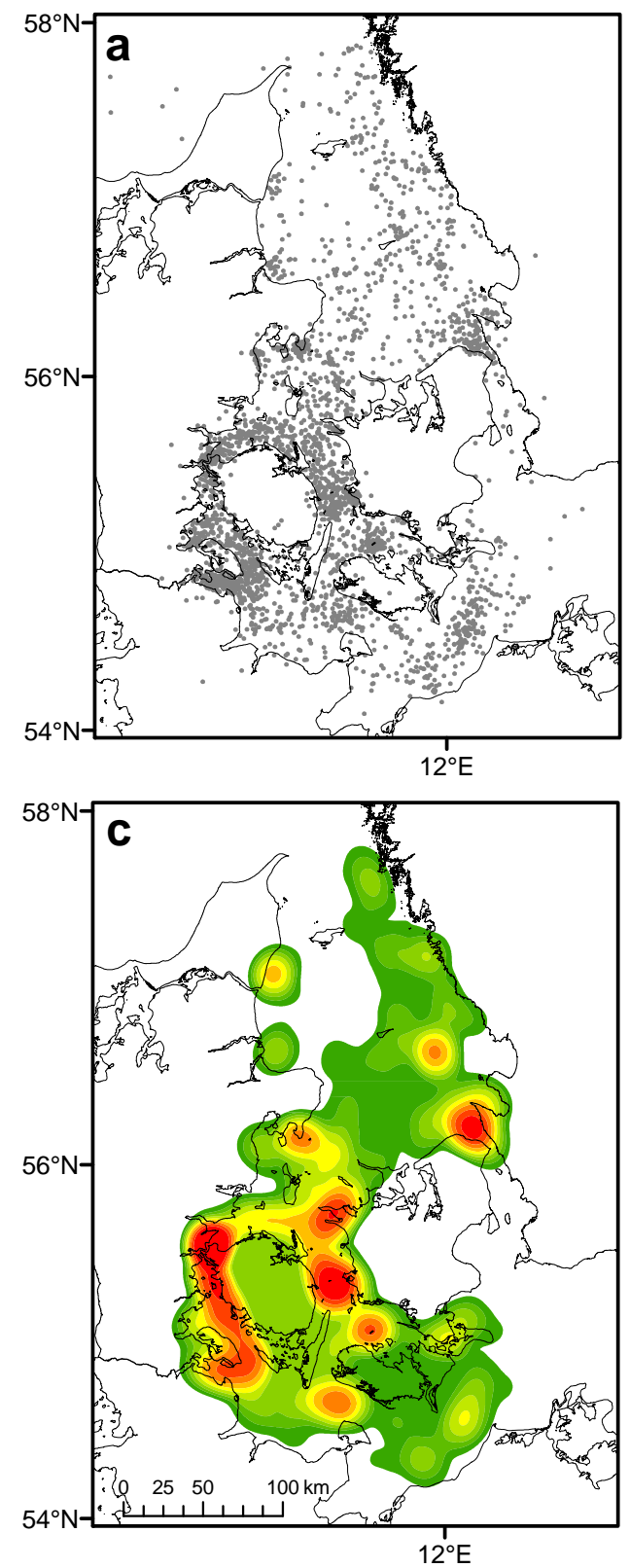

turned out to be too fragmented, the use of smoothing factor 20,000 and 30,000 both appeared suitable in regard to our knowledge of harbor porpoise habitats i.e. the kernel areas are relatively large and coherent (Fig.S3C and Fig.S3d). We decided on smoothing factor 20,000, which includes less land areas and did not seem to smooth out small high density area e.g. Store Middelgrund and Northern Samsø Belt.
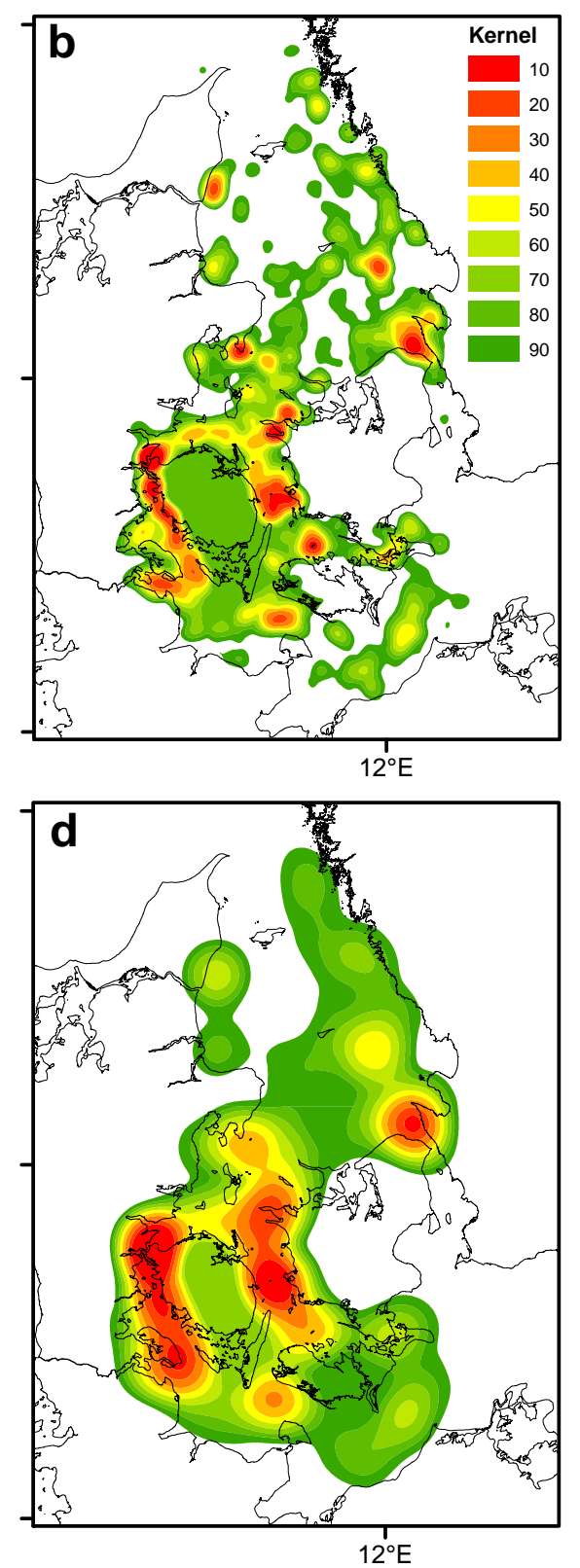

Figure S3. Comparison of smoothing factor used in Kernel density estimation of utilization distribution. a) Argos locations from tagged harbor porpoises 1997-2007, b) Kernel density estimate using smoothing factor 10,000, c) Kernel density estimate using smoothing factor 20,000, and d) Kernel density estimate using smoothing factor 30,000. 


\section{APPENDIX 4. GLOBAL VERSUS LOCAL ESTIMATES OF DENSITY}

The relative size and form of the kernel density estimation grid is dependant on the total number of locations and their distribution. For instance, if individual porpoises are removed or added to the analy-sis, the size and shape of the kernel density surface will change in all areas because the kernel density estimator includes all locations in the calculations.

To challenge the validity of the high density areas determined by the kernel density estimator, re-sults were compared to results obtained for the same data using a grid-based method, which takes into account the inaccuracy on each Argos location and where each grid cell is independent of other grid cells and the total number of locations (Tougaard et al. 2008). This grid analysis divided the study area into $4 \times 4 \mathrm{~km}$ squares and calculated the most likely number of true locations inside each square by weighting each location according to the accuracy of the associated location class. The method has two advantages over the kernel density analysis:

1. Each estimate is a local estimate, whose value depends only on locations within the grid cell and immediately neighboring cells. Thus, in contrast to kernel methods, where the whole dataset is in-cluded in the calculations, and data geographically far apart influence each other, the grid method produces results independent of other cells. The grid method was applied using weight on each porpoise (Fig. S4).

2. The grid method includes the inaccuracy in Argos location classes as found by (Vincent et al. 2002), in the Grid analysis. For each Argos location within a $4 \times 4 \mathrm{~km}$ square grid cell the likelihood that the porpoise was actually within that cell is calculated and the value added to the cell. Likewise, the likelihood that it was actually in one of the

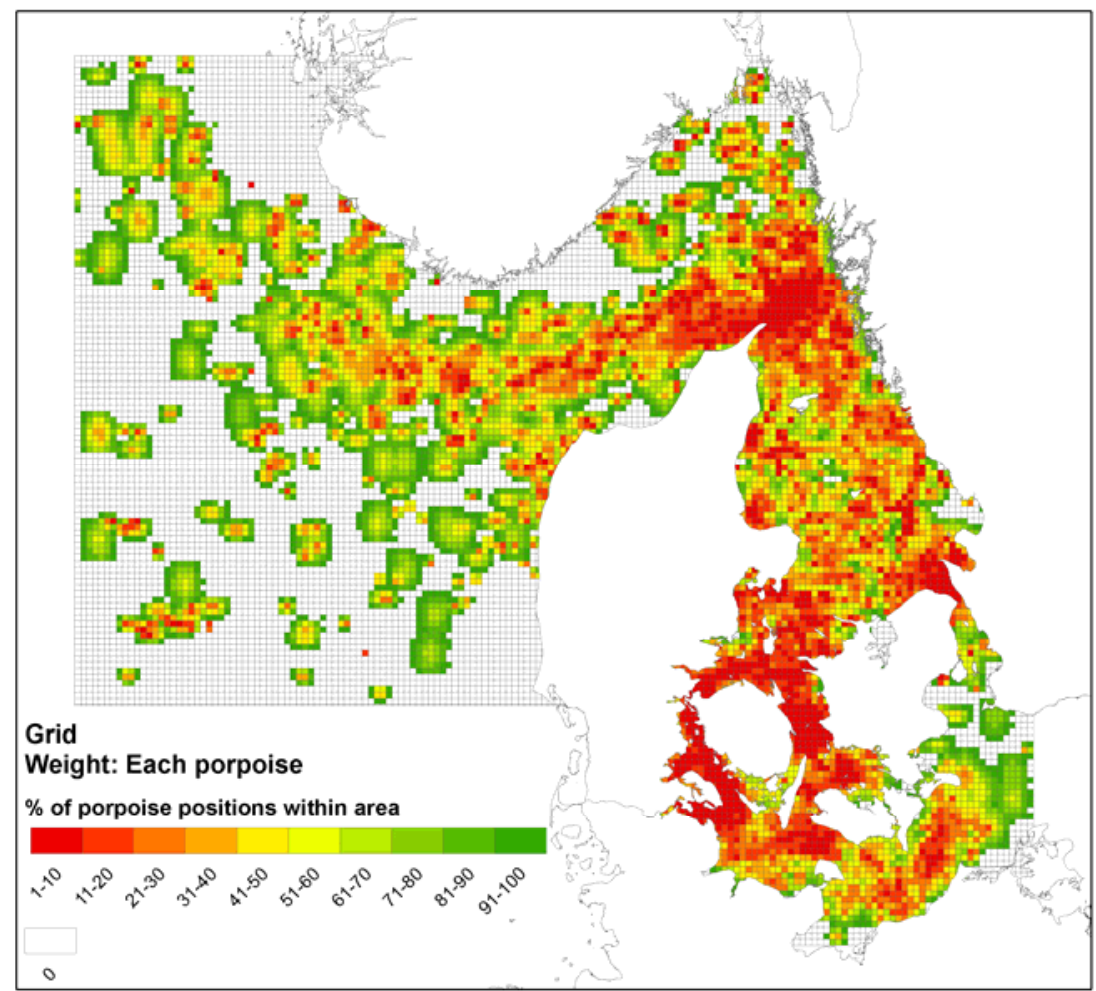

Figure S4. Distribution of porpoises tagged in Danish waters between 1997 and 2007 ( $N=64$ porpoises, $n=4309$ locations). Grid analysis weighted by individual porpoise. Map projection universal transverse Mercator, Zone 32N, WGS84. 
neighboring cells is calculated and that value added to those cells. When all values are added up a grid including the Argos inaccuracy is produced (Fig. S4).

When comparing the maps of the kernel (Fig.S2) and the grid (Fig.S3) analysis, a good overall corre-spondence with respect to high and low density areas is found. Furthermore, when examining the cor-relation further and including the entire study area (12,316 cells) a correlation of R2 $=0.54$ is found, Fig S5. The residual variation from the regression line in Fig S5 is caused by the spatial smoothing by the kernel density estimation procedure. This smoothing is desired for the purpose of this study when des-ignating larger and spatially more contiguous areas as MPA candidates. Thus we choose to use kernel estimation grid with weight to each porpoise for presenting high density areas.

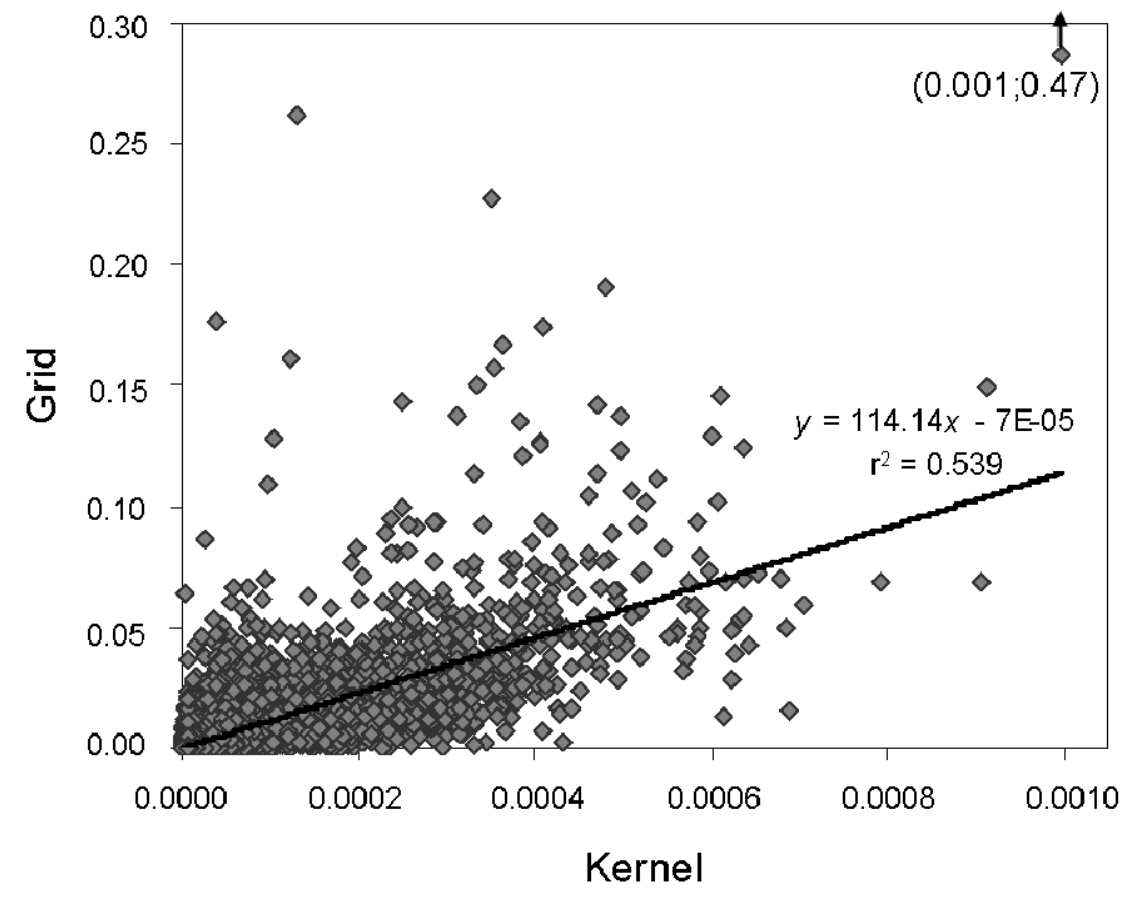

Figure S5. Correlation between the kernel density estimation and the grid analysis. Trend line, equation and $R$-square is shown $(R 2=0.54)$.

\section{REFERENCES}

Blundell, G. M., J. A. K. Maier, and E. M. Debevec. 2001. Linear home ranges: Effects of smoothing, sample size, and autocorrelation on kernel estimates. Ecological Monographs 71:469-489.

Douglas D. 2006. The Douglas Argos-Filter Algorithm, Version 7.03. U.S. Geological Survey, Anchorage, Alaska.

Freitas, C., C. Lydersen, M. A. Fedak, and K. M. Kovacs. 2008. A simple new algorithm to filter marine mammal Argos locations. Marine Mammal Science 24:315-325.
Tougaard, J., J. Teilmann, and S. Tougaard. 2008. Harbour seal spatial distribution estimated from Argos satellite telemetry - overcoming positioning errors. Endangered Species Research 4:113122.

Vincent, C., B. J. McConnell, V. Ridoux, and M. A. Fedak. 2002. Assessment of Argos location accuracy from satellite tags deployed on captive gray seals. Marine Mammal Science 18:156-166.

Worton, B. J. 1989. Kernel Methods for Estimating the Utilization Distribution in Home-Range Studies. Ecology 70:164-168. 